\title{
ANÁLISE ECONÔMICA DA APLICAÇÃO DE ESCÓRIA SINTÉTICA SINTERIZADA NO REFINO SECUNDÁRIO DO AÇO*
}

José Flávio Viana ${ }^{1}$ Marcus Novaes Motta ${ }^{2}$

\section{Resumo}

A redução do custo de fabricação do aço tem como ponto importante o refino secundário, seja com a utilização do Forno Panela, aquecimento químico ou borbulhamento de argônio. A qualidade e tempo de formação da escória sintética tem relação direta com 0 custo do tratamento. As escórias sintéticas sinterizadas produzidas pela Tecnosulfur contribuem significativamente para a redução do custo total de tratamento do aço nesta etapa.

Palavras-chave: Escória sinterizada; Escória sintética; Refino secundário.

\section{ECONOMIC ANALYSIS OF THE USE OF SINTERED SLAG IN THE STEEL SECONDARY REFFINING}

\section{Abstract}

One important point of the cost of liquid steel production is the secondary refining, by ladle furnace, chemical heating or argon bubbling. The quality and time request for the slag formation have direct influence on the treatment cost. The sintered synthetic slags supplied by Tecnosulfur have a significant weight to the total treatment cost reduction on this stage of the steelmaking.

Keywords: Synthetic slag; Sinter slag; Secondary refining.

1 Engenheiro Metalurgista, MSc, CQE, CQA, Gerente Técnico, Tecnosulfur S/A, Sete Lagoas-MG, Brasil.

2 Engenheiro Metalurgista, Engenheiro de Processo, Tecnosulfur S/A, Sete Lagoas-MG, Brasil. 


\section{INTRODUÇÃO}

A indústria busca continuamente a melhoria da eficiência. A necessidade de redução de custos tem um peso variável cíclico, mas está sempre presente nos objetivos de qualquer atividade. Na siderurgia não é diferente e em especial nos processos de fabricação de aço nas aciarias.

O refino secundário tem hoje papel fundamental no processo de fabricação dos aços. Do simples ajuste da composição química, que era o objetivo inicial desta etapa, ele passou também a fazer parte do processo produtivo, como por exemplo no caso da desgaseificação, para redução dos teores de hidrogênio e carbono, ou em fornos panelas ou estações de injeção de finos para redução dos teores de enxofre.

Assim como no refino primário, é necessária a utilização de uma escória, que em equilíbrio com o metal líquido, propicia a fixação do enxofre e dos óxidos, que no seio metálico, formariam inclusões ${ }^{(2)}$.

O custo do tratamento do aço no refino secundário envolve diversos parâmetros. Desde a energia gasta para manutenção ou elevação da temperatura do aço líquido, pelo consumo de refratários, especialmente das panelas, pelo consumo das ligas desoxidantes, pelos fundentes utilizados para formação da escória sintética e finalmente, pela recusa ou defeitos dos aços produzidos. A produtividade deve ser também considerada, quando a demanda de aço no mercado está favorável.

Deste o ano de 2000, a Tecnosulfur vem desenvolvendo a produção de escórias sintéticas sinterizadas. As escórias sintéticas sinterizadas (marca TECSLAG ${ }^{\circledR}$ ) possuem características de homogeneidade, ponto de fusão adequado ao processo, baixa higroscopicidade e podem ser fornecidas customizadas, portanto, adequadas a cada processo específico do cliente.

O processo de fabricação da escória sintética sinterizada na Tecnosulfur ${ }^{(3)}$ passou por diversas etapas, desde um processo por bateladas, depois por uma pequena planta de sinterização contínua e finalmente, com a instalação de uma máquina de sinterização com maior capacidade de produção. Hoje, pode ser ofertada ao mercado mais de 4000 toneladas mensais de escória sintética sinterizada. A nova planta instalada possibilitou a redução dos custos de fabricação, colocando a Tecnosulfur na condição de contribuir com a redução dos custos de tratamento dos aços no refino secundário.

Este trabalho tem como objetivo mostrar como a escória sintética sinterizada pode contribuir com a redução do custo de fabricação do aço no refino secundário e, desta forma, contribuir para a melhoria da eficiência da fabricação de aço.

\section{MATERIAIS E MÉTODOS}

Para o desenvolvimento de uma escória sintética sinterizada são necessários dados do processo que permitam chegar uma composição química levando em consideração todas as entradas de óxidos do processo e a finalidade do tratamento do aço no refino secundário. A escória sintética sinterizada desenvolvida é então utilizada no processo do cliente.

A Figura 1 apresenta esquematicamente os dados levantados do processo de fabricação do aço líquido, desde o vazamento no Forno Elétrico ou Convertedor, até o final de tratamento no refino secundário. 


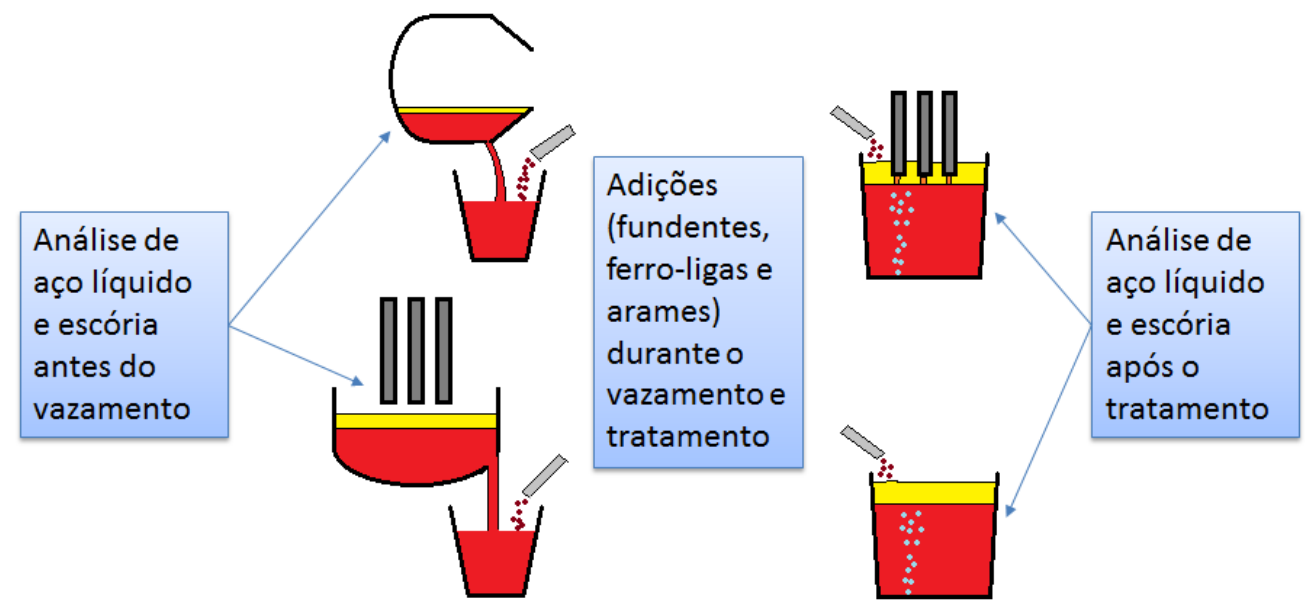

Figura 1 - Dados coletados durante o acompanhamento do processo

A comparação econômica do processo utilizando a escória sintética sinterizada e a escória convencional, é feita considerando os seguintes parâmetros:

- Consumo de energia elétrica do Forno Panela;

- Consumo de eletrodos do Forno Panela;

- Consumo de ligas desoxidantes;

- Consumo de fundentes para formação da escória;

- Consumo de refratário das panelas de aço.

Para processos que não possuem o Forno Panela no refino secundário, a economia de energia vai se refletir na redução do consumo de alumínio, utilizado para aquecimento em processos de aquecimento químico, como CAS-OB, IRUT ou AHF. Mesmo quando se utiliza somente uma estação de borbulhamento de argônio, a utilização da escória sintética sinterizada reduz a temperatura necessária no aço, antes do início de tratamento, graças à homogeneização da escória sintética sinterizada e seu menor ponto de fusão em relação aos fundentes adicionados, quando não se utiliza a escória sintética sinterizada(1).

Outros parâmetros podem também ser considerados para análise, dependendo do processo e das características de cada planta analisada, como:

- Perdas de fundentes para o sistema de despoeiramento;

- Perdas de corridas por composição química fora da especificação;

- Geração de sucata do aço lingotado por defeitos;

- Redução da necessidade de desgaseificação;

- Aumento da disponibilidade de silos de fundentes;

- Produtividade da aciaria.

Estes parâmetros, muitas vezes, são mais difíceis de serem mensurados, pois envolvem outras áreas, como lingotamento, laminação, área de manuseio de rejeitos. Outros dependem de uma análise da redução da necessidade de investimentos, como o caso da redução da necessidade de desgaseificação ou disponibilidade de silos de fundentes. O parâmetro produtividade, muitas vezes depende da época de estudo, já que está ligado diretamente à demanda de aço no mercado.

A Tabela 1 apresenta os dados iniciais que devem ser levados em consideração para o levantamento de comparação dos custos de tratamento com e sem a utilização da escória sintética sinterizada. 
Tabela 1: Dados iniciais para cálculo do custo de tratamento

\begin{tabular}{|l|c|}
\hline Variáveis & Unidade \\
\hline Peso de carga da panela de aço & tonelada \\
\hline Vida de panelas de aço & número \\
\hline Tap-to-tap forno panela & minuto \\
\hline Produção diária (corridas) & número \\
\hline Consumo de energia Forno Panela & $\mathrm{kWh} /$ tonelada \\
\hline Consumo de eletrodos Forno Panela & $\mathrm{Kg} /$ tonelada \\
\hline Consumo de cal calcítica & $\mathrm{kg} /$ corrida \\
\hline Consumo de cal dolomítica & $\mathrm{kg} /$ corrida \\
\hline Consumo de MgO & $\mathrm{kg} /$ corrida \\
\hline Consumo de Fluorita & $\mathrm{kg} /$ corrida \\
\hline Consumo de aluminato de cálcio & $\mathrm{kg} /$ corrida \\
\hline Consumo de FeSi/FeSiMn & $\mathrm{kg} /$ tonelada \\
\hline Consumo de alumínio & $\mathrm{kg} /$ tonelada \\
\hline Consumo de carbureto de cálcio & $\mathrm{kg} /$ tonelada \\
\hline Outras ligas & $\mathrm{kg} /$ tonelada \\
\hline Outro tipo de escória sintética & $\mathrm{kg} /$ tonelada \\
\hline Geração de poeira durante o vazamento & $\mathrm{kg} /$ tonelada \\
\hline Reclassificação por S fora de faixa & $\%$ \\
\hline Perda na escarfagem por defeito & $\%$ \\
\hline Perda de fundentes no transporte/despoeiramento & $\%$ \\
\hline Eliminação da necessidade de desgaseificação & Sim/Não \\
\hline Liberação de silos de fundentes & número \\
\hline
\end{tabular}

Para cálculo da influência de cada uma das variáveis apresentadas na Tabela 1, devese levar em consideração os custos de cada variável que impacta no custo total de produção do aço. A tabela 2 apresenta a relação destas variáveis de custo. 
Tabela 2 - Custo de cada variável para cálculo do custo final de fabricação

\begin{tabular}{|c|c|}
\hline Variáveis & Unidade \\
\hline Custo energia elétrica & $\mathrm{R} \$ \mathrm{kWh}$ \\
\hline Custo eletrodos & $\mathrm{R} \$ / \mathrm{kg}$ \\
\hline Custo da cal calcítica & $\mathrm{R} \$$ /tonelada \\
\hline Custo da cal dolomítica & $\mathrm{R} \$ /$ tonelada \\
\hline Custo do MgO & $\mathrm{R} \$ /$ tonelada \\
\hline Custo da Fluorita & $\mathrm{R} \$ /$ tonelada \\
\hline Custo de aluminato de cálcio & $\mathrm{R} \$ /$ tonelada \\
\hline Custo de refratários de panela & $\mathrm{R} \$ / \mathrm{t}$ capacidade \\
\hline Custo do FeSi e FeSiMn & $\mathrm{R} \$ /$ tonelada \\
\hline Custo do Alumínio & $\mathrm{R} \$ /$ tonelada \\
\hline Custo do CaC2 & $\mathrm{R} \$ /$ tonelada \\
\hline Custo de Outras ligas & $\mathrm{R} \$ /$ tonelada \\
\hline $\begin{array}{l}\text { Custo da disposição de poeira gerada durante o } \\
\text { vazamento }\end{array}$ & $\mathrm{R} \$ /$ tonelada \\
\hline Custo investimento em silos de fundentes & $\mathrm{R} \$ /$ silo \\
\hline Custo da necessidade de desgaseificação & $\mathrm{R} \$ /$ tonelada \\
\hline Custo de outro tipo de escória sintética & $\mathrm{R} \$ /$ tonelada \\
\hline
\end{tabular}

Após o desenvolvimento da escória sintética sinterizada, é realizado um teste de aplicação do produto. Os resultados obtidos durante a realização deste teste, irão determinar as novas condições operacionais, com a utilização da escória Tecnosulfur. A Tabela 3 apresenta a relação das melhorias esperadas com a utilização do produto.

Tabela 3 - Melhorias esperadas com utilização da escória Tecnosulfur

\begin{tabular}{|l|c|}
\hline Aumento da vida de panelas & $\%$ \\
\hline Redução do consumo de energia elétrica & $\%$ \\
\hline Redução do consumo de eletrodos & $\%$ \\
\hline Redução da reclassificação do aço por alto S & $\%$ \\
\hline Redução da geração de sucata por defeitos & $\%$ \\
\hline Perda de fundentes no despoeiramento & minuto \\
\hline Redução do tap-to-tap & $\%$ \\
\hline Redução do consumo de desoxidantes & $\%$ \\
\hline Redução do consumo de outras ligas & $\%$ \\
\hline Redução de poeira durante o vazamento & $\%$ \\
\hline Utilização da desgaseificação & número \\
\hline Aumento da disponibilidade de silos & \\
\hline
\end{tabular}

Com todos os dados obtidos, juntamente com o cliente, desde as condições iniciais, Tabelas 1 e 2, os resultados operacionais com e sem a utilização da escória sintética sinterizada e a determinação das melhorias obtidas, é possível a comparação do custo total de produção. 


\section{RESULTADOS E DISCUSSÃO}

Para apresentação dos resultados, foram utilizados dados de dois processos, onde foi desenvolvida a escória sintética sinterizada. Os dois casos, são de aciarias elétricas que utilizam o forno panela como refino secundário. Nestes casos não há produção de aços especiais e pode-se notar as vantagens de utilização da escória sintética sinterizada, somente levando-se em consideração as economias operacionais decorrentes das reduções de custo de energia, eletrodos, ferro-ligas e refratários. Também não foram verificados ganhos relativos à produtividade, já que o tempo de operação dos fornos elétricos não permitia o aumento de produção. Os dados de custos comparativos estão apresentados em base 100 .

\subsection{Processo A}

A escória sintética sinterizada foi aplicada em uma aciaria elétrica cuja a capacidade da panela é de 65 toneladas. No processo anterior, utilizava-se somente cal e fluorita para formação de escória. O teor de $\mathrm{MgO}$ da escória final era obtido somente através do $\mathrm{MgO}$ contido na escória passante do forno elétrico. A redução do consumo de desoxidantes é devida à redução da oxidação no forno elétrico, já que com formação de escória mais rapidamente, ocorreu a redução do tempo de tratamento e das perdas térmicas.

A Tabela 4 apresenta as reduções de custo obtidas neste processo. Nota-se, que para as variáveis consideradas, ocorreu uma redução de $5,05 \%$ no custo, mesmo com o aumento no custo de fundentes para formação de escória aumentando em 119\%!

Tabela 4 - Comparação de custos com e sem aplicação da escória sinterizada

\begin{tabular}{|l|c|c|c|}
\hline \multicolumn{1}{|c|}{ Variável } & Normal & TECSLAG & Diferença \\
\hline Consumo de energia elétrica & 7,97 & 5,58 & 30,0 \\
\hline Consumo de eletrodos & 4,24 & 2,97 & 30,0 \\
\hline Consumo de fundentes & 4,51 & 9,87 & $-119,0$ \\
\hline Consumo de desoxidantes & 75,01 & 69,01 & 8,0 \\
\hline Consumo de refratários & 8,27 & $\mathbf{7 , 5 2}$ & 9,1 \\
\hline \multicolumn{1}{|c|}{ Total } & $\mathbf{1 0 0}$ & $\mathbf{9 4 , 9 5}$ & $\mathbf{5 , 0 5}$ \\
\hline
\end{tabular}

A escória sintética sinterizada deste processo foi ajustada com o principal objetivo de promover a dessulfuração do aço, durante o tratamento no forno panela. A escória utilizada possui como componentes $\mathrm{CaO}, \mathrm{MgO}$ e $\mathrm{CaF}_{2}$ e o consumo específico é de $6,25 \mathrm{~kg} / \mathrm{ton}$. A Tabela 5 apresenta as características desta escória.

Tabela 5 - Características da escória sintética sinterizada utilizada no processo A

\begin{tabular}{|c|c|c|c|c|c|c|}
\hline \multicolumn{5}{|c|}{ Especificação química (\%) } & $\begin{array}{c}\text { Proporção } \\
\text { líquida (\%) }\end{array}$ & Viscosidade \\
\hline $\mathrm{CaO}$ & $\mathrm{MgO}$ & $\mathrm{CaF}_{2}$ & $\mathrm{SiO}_{2}$ & $\mathrm{Al}_{2} \mathrm{O}_{3}$ & à $1600^{\circ} \mathrm{C}$ & $($ Pa.s) \\
\hline $40-70$ & $5-15$ & $10-20$ & $5 \mathrm{max}$ & $5 \mathrm{max}$ & 48 & 0,033 \\
\hline
\end{tabular}




\subsection{Processo B}

O Processo $B$ se refere a, também, uma aciaria elétrica, refino secundário com forno panela. A capacidade da panela é de 25 toneladas. Os aços produzidos são destinados à produção de vergalhões para a construção civil. Os resultados de custo apresentados na Tabela 6 , em base 100, se referem à medida de um mês de produção, utilizando a escória sintética sinterizada e outro mês sem a escória, utilizando como fundentes, cal calcítica, cal dolomítica e fluorita.

Neste processo, o desenvolvimento da composição química da escória sinterizada, visou a saturação da escória em MgO para melhoria da vida de panelas, mantendo a capacidade de dessulfuração. Neste processo, onde era utilizado como desoxidantes, além do FeSi e FeSiMn o carbureto de cálcio. Com a utilização da escória sintética sinterizada foi observada a redução de todos os desoxidantes. A Tabela 6 apresenta os resultados obtidos neste processo.

Tabela 6 - Comparação de custos com e sem aplicação da escória sinterizada

\begin{tabular}{|l|c|c|c|}
\hline \multicolumn{1}{|c|}{ Variável } & Normal & TECSLAG & Diferença \\
\hline Consumo de energia Total & 11,85 & 10,07 & 15,0 \\
\hline $\begin{array}{l}\text { Consumo de eletrodos Forno } \\
\text { Panela }\end{array}$ & 0,32 & 0,27 & 15,0 \\
\hline Consumo de fundentes & 5,07 & 7,26 & $-43,3$ \\
\hline Consumo de desoxidantes & 68,89 & 62,00 & 10,0 \\
\hline Consumo de refratários & 13,87 & 7,84 & 43,5 \\
\hline \multicolumn{1}{|c|}{ Custo final } & $\mathbf{1 0 0 , 0 0}$ & $\mathbf{8 7 , 4 4}$ & $\mathbf{1 2 , 6}$ \\
\hline
\end{tabular}

Da mesma forma que no processo 1 , ocorreu redução significativa dos custos relacionados à formação de escória no tratamento do aço no refino secundário de $12,6 \%$, mesmo com a elevação do custo de fundentes, com a utilização da escória sintética sinterizada, onde o consumo específico foi de $8 \mathrm{~kg} / \mathrm{ton}$, e foi desenvolvida uma escória composta de $\mathrm{CaO}, \mathrm{MgO}$ e $\mathrm{CaF}_{2}$. A Tabela 7 apresenta as características desta escória.

Tabela 7 - Características da escória sintética sinterizada utilizada no processo B

\begin{tabular}{|c|c|c|c|c|c|c|}
\hline \multicolumn{5}{|c|}{ Especificação química (\%) } & $\begin{array}{c}\text { Proporção } \\
\text { líquida (\%) }\end{array}$ & Viscosidade \\
\hline $\mathrm{CaO}$ & $\mathrm{MgO}$ & $\mathrm{CaF}_{2}$ & $\mathrm{SiO}_{2}$ & $\mathrm{Al}_{2} \mathrm{O}_{3}$ & à $1600^{\circ} \mathrm{C}$ & $(\mathrm{Pa} . \mathrm{s})$ \\
\hline $40-70$ & $10-20$ & $10-20$ & $5 \mathrm{max}$ & $5 \mathrm{max}$ & 31 & 0,033 \\
\hline
\end{tabular}

\section{CONCLUSÃO}

Nos processos analisados neste trabalho, pode-se observar reduções significativas de custo total $(5,1 \%$ e $12,6 \%$, respectivamente), que foram obtidos graças à utilização da escória sintética sinterizada, TECSLAG ${ }^{\circledR}$, desenvolvida pela Tecnosulfur. A redução foi obtida considerando parâmetros básicos, como energia, eletrodos, desoxidantes e refratários. Para outros processos, pode-se levar em conta outros parâmetros como melhoria da qualidade do aço e produtividade, acentuando ainda mais, a importância da boa formação de escória na etapa do refino secundário com a utilização do produto sinterizado. 


\section{REFERÊNCIAS}

1 Viana JF et al. Estudo das Características de Fusão das Escórias Sintéticas Sinterizadas. In:43 Seminário de Aciaria da ABM, Maio de 2012, Belo Horizonte, MG, Brasil.

2 Costa, S.L.S. et al: "Desenvolvimento de escória sintética a partir de rejeitos industriais para tratamento de aços", (1999), 30 Seminário de Aciaria da ABM, Belo Horizonte.

3 Viana, J.F. et al: "Characteristics and application of sinterized chemical slag in steel shops”, (2009), 17 Conferencia de Acería, Campana, Argentina. 